\title{
Questes
}

vestes Revue pluridisciplinaire d'études médiévales

$20 \mid 2011$

Maris et femmes

\section{Maris et femmes : éléments bibliographiques}

Diane Chamboduc de Saint Pulgent et Blandine Longhi

\section{Q OpenEdition}

\section{Journals}

\section{Édition électronique}

URL : https://journals.openedition.org/questes/2448

DOI : 10.4000/questes. 2448

ISSN : 2109-9472

\section{Éditeur}

Les Amis de Questes

\section{Édition imprimée}

Date de publication : 15 février 2011

Pagination : 105-110

ISSN : 2102-7188

\section{Référence électronique}

Diane Chamboduc de Saint Pulgent et Blandine Longhi, « Maris et femmes : éléments

bibliographiques », Questes [En ligne], 20 | 2011, mis en ligne le 01 janvier 2014, consulté le 26 août 2021. URL : http://journals.openedition.org/questes/2448; DOI : https://doi.org/10.4000/questes. 2448 


\section{Éléments bibliographiques}

\section{Général}

\section{Histoire}

Bologne, Jean-Claude, Histoire du mariage en Occident, Paris, J.-C. Lattès, 1995.

Burguiere, André, «Famille», in André BuRguIERE (dir.), Dictionnaire des sciences historiques, Paris, PUF, 1986, p. 274-279.

Burguiere, André, Klapisch-Zuber, Christiane, Segalen, Martine, Zonabend, Françoise (dir.), Histoire de la famille, Paris, Armand Colin, 1986, 2 vol.

DuBy, Georges, LE GoFF, Jacques (dir.), Famille et parenté dans l'Occident médiéval, Rome, École Française de Rome, 1977.

Duby, Georges, Perrot, Michelle (dir.), Histoire des femmes en Occident, t. 2 : Le Moyen Âge, Paris, Plon, 1991.

La Femme dans les civilisations des $X^{e}$-XIII ${ }^{e}$ siècles. Actes du colloque tenu à Poitiers du 23 au 25 septembre 1976, Cahiers de civilisation médiévale, XX (1977).

Heuclin, Jean, Rouche, Michel (dir.), La Femme au Moyen Âge, Maubeuge, Publications Ville de Maubeuge, Paris, Diffusion J. Touzot, 1990.

KLAPISCH-Zuber, Christiane, «La famille médiévale», in Jacques DuPAQUIER (dir.), Histoire de la population française, Paris, PUF, 1988, t. 1, p. 463-512.

KlaPISCH-Zuber, Christiane (dir.), Histoire des femmes, Paris, Plon, 1991, t. 2.

\section{Littérature}

BusChINGER, Danielle, CREPIN, André (dir.), Amour, mariage et transgressions au Moyen Âge. Actes du colloque du Centre d'Études Médiévales de l'Université de Picardie, du 24 au 27 mars 1983, Göppingen, Kümmerle Verlag, 1984.

BuschINGER, Danielle, SPIEWOK Wolfgang (dir.), Sex, Love and Marriage in medieval Literature and Reality, $31^{\text {th }}$ International Congress on Medieval Studies an der Western Michigan University (Kalamazoo-USA), 8-12 mai 1996, Greifswald, Reineke Verlag, 1996.

CARTLIDGe, Neil, Medieval Marriage. Literary Approaches, 1100-1300, Cambridge, D. S. Brewer, 1997.

Classen, Albrecht (dir.), Discourses on Love, Marriage, and Transgression in Medieval and Early Modern Literature, Tempe, Arizona, Arizona Center for Medieval and Renaissance Studies, 2004.

Van Hoecke, Willy, Welkenhuysen, Andries (dir.), Love and Marriage in the Twelfth Century, Louvain, Leuven University Press, 1981.

Voaden Rosalynn, Wolfthal, Diane (dir.), Framing the Family. Narrative and Representation in the Medieval and Early Modern Periods, Tempe, Arizona, Arizona Center for Medieval and Renaissance Studies, 2005. 


\section{Science sociales}

DuMEZIL, Georges, Mariages indo-européens, Paris, Payot, 1979.

DURKHEIM, Émile, «Introduction à la sociologie de la famille», Annales de la Faculté des Lettres de Bordeaux, Paris, Ernest Leroux, 1888, vol. 10.

GoODY, Jack, L'Évolution de la famille et du mariage en Europe, traduit de l'anglais par Marthe BLINOFF, Paris, Armand Colin, 1985.

Hajnal, John, «European Marriage Patterns in Perspective», in David V. GLAss, David E. C. Eversley (dir.), Population in History: essays in historical demography, Londres, E. Arnold, 1965, p. 101-143.

HAREVEN, Tamara, «The family as a process : the historical study of the family cycle », Journal of Social History, 7 (1973-1974), p. 322-329.

HAREVEn, Tamara, Transitions : The Family and the Life Course in Historical Perspective, New York, Academic Press, 1978.

Kuenn, Thomas, Law, Family and Women. Toward a Legal Anthropology of Renaissance Italy, Chicago, Chicago University Press, 1994.

LeVI-STRAuss, Claude, Les Structures élémentaires de la parenté, Paris, PUF, 1949.

OuthwaIte, Richard B., Marriage and Society, Studies in the Social History of Marriage, Londres, Europa publications limited, 1981.

PARKIN, Robert, Kinship, An Introduction to Basic Concepts, Oxford, Blackwell, 1997.

SMITH, Robert M., "Some Reflections on the Evidence for the Origins of the "European Marriage Pattern" in England », in Christopher HARRIS (dir.), The Sociology of the Family, Keele, University of Keele Press, 1979, p. 74-112.

\section{Maris et femmes au Haut Moyen Âge}

LE JAN, Régine, Famille et pouvoir dans le monde franc (VII ${ }^{e} X^{e}$ siècle). Essai d'anthropologie sociale, Paris, Publications de la Sorbonne, 1995.

Il Matrimonio nella società altomedievale. Settimane di studio del centro italiano di studi sull'alto medioevo, avril 1976 (XXIV), Spolète, 1977, 2 vol.

RING, Richard R., «Early Medieval Peasant Households in Central Italy », Journal of Family History, vol. 4, ${ }^{\circ} 1$ (printemps 1979), p. 2-25.

SoT, Michel, «Historiographie épiscopale et modèle familial en Occident au IX ${ }^{\mathrm{e}}$ siècle », Annales ESC, $33^{\text {ème }}$ année, $n^{\circ} 3$ (mai-juin 1978), p. 433-449.

THEIS, Laurent, « Saints sans famille ? Quelques remarques sur la famille dans le monde franc à travers les sources hagiographiques », Revue historique, t. CCLV, n 517 (janvier-mars 1976), p. 3-20. 


\section{Le mariage : théories et réglementations}

Andre LE Chapelain, Traité de l'amour courtois, Claude Buridant (éd.), Paris, Klincksieck, 1974.

BENVENISTE, Henriette, «Les enlèvements : stratégies matrimoniales, discours juridique et discours politique en France à la fin du Moyen Âge », Revue historique, t. CCLXXXIII, $\mathrm{n}^{\circ} 573$ (janvier-mars 1990), p. 13-35.

Brundage, James A., Law, Sex and Christian Society in Medieval Europe, Chicago, University of Chicago Press, 1987.

ESMEIN, Adhémar, Le Mariage en droit canonique, 2 volumes, $2^{\text {ème }}$ édition mise à jour par Robert Genestal et Jean DAUVILLIER, Paris, Librairie du Recueil Sirey, 1929-1935.

GAUDEMET, Jean, Le Mariage en Occident. Les mours et le droit, Paris, Cerf, 1987.

LEDWIGE, Francis, «Relations de famille dans la correspondance de Gerson », Revue historique, t. CCLXXI, nº 549 (janvier-mars1984), p. 3-23.

SheEHAN, Michael M., Marriage, Family and Law in Medieval Europe : Collected Studies, Cardiff, University of Wales Press, 1996.

\section{Couple conjugal et société}

ADAIR, Richard, Courtship, Illegitimacy and Marriage in Early Modern England, Manchester/New York, Manchester University Press, 1996.

CARLIER, Myriam, Soens, Tim (dir.), The Household in Late Medieval Cities, Italy and Northwestern Europe Compared, Louvain/Apeldoorn, Garant, 2001.

Courtemanche, Andrée, La Richesse des femmes. Patrimoine et gestion à Manosque au XIV $V^{e}$ siècle, Paris/Montréal, Vrin/Bellarmin, 1993.

DANNEEL, Marianne, «Gender and the Life Course in the Late Medieval Flemish Town » in Wim Blockmans, Marc Boone, Thérèse De Hemptinne (dir.), Secretum Scriptorum. Liber alumnorum Walter Prevenier, Louvain/Apeldoorn, Garant, 1999.

DuBY, Georges, Le Chevalier, la femme et le prêtre. Le mariage dans la France féodale, Paris, Hachette, 1981.

DuBY, Georges, «Le lignage, $\mathrm{X}^{\mathrm{e}}-\mathrm{XIII}{ }^{\mathrm{e}}$ siècles », in Pierre NORA (dir.), Les Lieux de mémoire, t. II, La Nation, Paris, Gallimard, 1986, p. 31-56.

Famille et société, numéro spécial des Annales ESC, $27^{\text {ème }}$ année, no $4-5$ (juillet-octobre 1972).

Femmes Mariages-Lignages (XII ${ }^{e}$-XIV ${ }^{e}$ siècles). Mélanges offerts à Georges Duby, Bruxelles, De Boeck Université, 1992.

Fleming, Peter, Family and Household in Medieval England, New York, Palgrave, 2001.

GAUCHER, Élisabeth, La Biographie chevaleresque. Typologie d'un genre (XIII $-X V^{e}$ siècle), $3^{\text {ème }}$ partie, chap. II, « Amour et mariage », Paris, Champion, 1994.

GAudemet, Jean, Les Communautés familiales, Paris, Marcel Rivière et Cie, 1963.

Greilsammer, Myriam, L'envers du tableau. Mariage et maternité en Flandre médiévale, Paris, Armand Colin, 1990. 
HeERs, Jacques, Le Clan familial au Moyen Âge. Étude sur les structures politiques et sociales des milieux urbains, Paris, PUF, 1974.

HeRlihy, David, Klapisch-Zuber, Christiane, Les Toscans et leurs familles. Une étude du catasto florentin de 1427, Paris, Presses de la Fondation nationale des Sciences Politiques, 1978.

Herlihy, David, Medieval Households, Cambridge, Harvard University Press, 1985.

JАСOB, Robert, Les Époux, le seigneur et la cité. Coutume et pratiques matrimoniales des bourgeois et des paysans de France du Nord au Moyen Âge, Bruxelles, Publications des Facultés universitaires Saint-Louis, 1990.

JoCHENS, Jenny M., «En Islande médiévale : à la recherche de la famille nucléaire », Annales $E S C, 40^{\text {ème }}$ année, $\mathrm{n}^{\circ} 1$ (janvier-février 1985), p. 95-112.

Kertzer, David I., SAller, Richard P. (dir.), The Family in Italy from Antiquity to the Present, New Haven, Yale University Press, 1993.

Klapisch-Zuber, Christiane, Women, Family, and Ritual in Renaissance Italy, Chicago, University of Chicago Press, 1985.

Klapisch-Zuber, Christiane (dir.), Liens de famille. Vivre et choisir sa parenté, Médiévales, $\mathrm{n}^{\circ} 19$ (automne 1990).

Klapisch-Zuber, Christiane, La Maison et le nom. Stratégies et rituels dans l'Italie de la Renaissance, Paris, Éditions de l'EHESS, 1990.

LETT, Didier, Famille et parenté dans l'Occident médiéval, $V^{e}-X V^{e}$ siècle, Paris, Hachette, 2000.

MitTerauer, Michael, Sieder, Reinhard, The European Family : Patriarchy to Partnership, 1400 to the Present, traduit de l'allemand par Karla OOSTERVEEN et Manfred Horzinger, Chicago, Chicago University Press, 1983.

Le Modèle familial européen. Normes, déviances, contrôle du pouvoir. Actes des séminaires organisés par l'École française de Rome et l'Università di Roma (1984), Rome, École française de Rome, 1986.

MurRAy, James M., «Family, Marriage and Moneychanging in Medieval Bruges », Journal of Medieval History, vol. 14, $\mathrm{n}^{\circ} 2$ (juin 1988), p. 115-125.

OTIS-Cour, Leah, "Mariage d'amour, charité et société dans les "romans de couple" médiévaux », Le Moyen Âge, t. CXI (2005), p. 275-291.

PreVenier, Walter (dir.), Marriage and Social Mobility in the Late Middle Ages. Actes du colloque de Gand, 18 avril 1988, Studia historica gandensia, 274 (1992).

RAZI, Zvi, Life, Marriage and Death in a Medieval Parish. Economy, Society and Demography in Halesowen (1270-1400), Cambridge, Cambridge University Press, 1980.

Les Relations de parenté dans le monde médiéval, Senefiance $\mathrm{n}^{\circ} 26$, publications $\mathrm{du}$ CUERMA, Aix-en-Provence, 1986.

SmaIL, Daniel L., «Démanteler le patrimoine. Les femmes et les biens dans la Marseille médiévale », Annales HSS, $52^{\text {ème }}$ année, n 2 (mars-avril 1997), p. 343-368.

Stella, Alessandro (dir.), Les Dépendances au travail, Médiévales $\mathrm{n}^{\circ} 30$ (printemps 1996).

Teyssot, Josiane (dir.), Le Mariage au Moyen Âge (XI $-X V^{e}$ siècles), Actes du colloque de Montferrand du 3 mai 1997, Clermont-Ferrand, Université Blaise Pascal, 1997. 


\section{Intimité du couple}

ARIES, Philippe, Duby, Georges (dir.), Histoire de la vie privée, t. 2 : De l'Europe féodale à la Renaissance, Paris, Seuil, 1985.

COMBARIEU Du GRES, Micheline de, L'Idéal humain et l'expérience morale chez les héros des chansons de geste, $2^{\text {ème }}$ partie, «Le Moi et l'Autre», Publications Université de Provence, diffusion Champion, 1979.

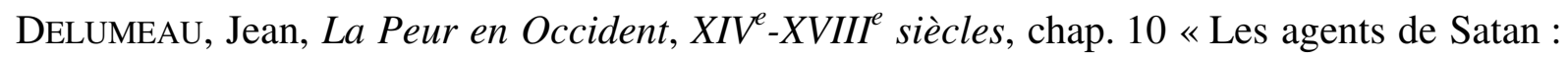
III - La femme », Paris, Fayard, 1978.

DuBy, Georges, Mâle Moyen Âge : de l'amour et autres essais, Paris, Flammarion, 1987.

DUfOURNET, Jean, «Les Relations de l'homme et de la femme dans les fabliaux : un double discours », in Femmes Mariages-Lignages (XII ${ }^{e}$-XIV $V^{e}$ siècles). Mélanges offerts à Georges Duby, Bruxelles, De Boeck Université, 1992, p. 103-123.

EDWARDs, Robert R., Spector, Stephen (dir.), The Old Daunce. Love, Friendship, Sex and Marriage in the Medieval World, New York, State University of New York Press, 1991.

FLANDRIN, Jean-Louis, Le Sexe et l'Occident. Évolution des attitudes et des comportements, Paris, Seuil, 1981.

FLANDRIN, Jean-Louis, Un temps pour embrasser. Aux origines de la morale sexuelle occidentale ( $V I^{e}-X I^{e}$ siècles), Paris, Seuil, 1983.

FLANDRIN, Jean-Louis, Familles, parenté, maison, sexualité dans l'ancienne société, Paris, Seuil, 1984.

Foucault, Michel, Histoire de la sexualité, Paris, Gallimard, 1976-1984.

HERLIHY, David, «The Making of the Medieval Family: Symmetry, Structure and Sentiment», Journal of Family History, numéro spécial: Religion and the Family in European History, vol. 8, n 2 (été 1983), p. 116-130.

JEAY, Madeleine, «Sexuality and Family in Fifteenth-Century France : are Literary Sources a Mask or a Mirror ? », Journal of Family History, vol. 4, n 4 (décembre 1979), p. 328-345.

KLASSEN, John, «The Development of the Conjugal Bond in Late Medieval Bohemia », Journal of Medieval History, vol. 13, ${ }^{\circ} 2$ (juin 1987), p. 161-178.

Nicholas, David, The Domestic Life of a Medieval City : Woman, Children and the Family in Fourteenth-Century Ghent, Lincoln, London, University of Nebraska Press, 1985.

ReY-Flaud, Henri, Le Charivari. Les rituels fondamentaux de la sexualité, Paris, Payot, 1985.

Rouche, Michel (dir.), Mariage et sexualité au Moyen Âge, Accord ou crise ?, Actes du colloque international de Conques, Paris, Presses de l'Université de Paris-Sorbonne, 2000.

Wathelet-WiLlem, Jeanne, «Guibourc, femme de Guillaume », in Les Chansons de geste du cycle de Guillaume d'Orange, t. III, Les Moniages Guibourc. Hommage à Jean Frappier, Paris, SEDES, 1983, p. 335-356.

\section{Relations conjugales et fonctionnement du texte littéraire}

CopPIN, Joseph, Amour et mariage dans la littérature française du Nord au Moyen Âge, Paris, Librairie d'Argences, 1961. 
CROISY-NAQUET, Catherine, «Mères, filles et sœurs; amantes, épouses et veuves dans le Roman de Thèbes », in Bernard RiBEMONT (dir.), Études sur le Roman de Thèbes : Qui des sept arz set rien entendre..., Orléans, Paradigme, 2002, p. 159-174.

JonIN, Pierre, Les Personnages féminins dans les romans français de Tristan au XII siècle. Étude des influences contemporaines, Gap, Ophrys, 1958.

NicKOLAUS, Keith, Marriage fictions in Old French secular narratives, 1170-1250 : a critical re-evaluation of the Courtly Love debate, New-York, Routledge, 2002.

Noble, Peter, Love and Marriage in Chrétien de Troyes, Cardiff, University of Wales Press, 1982.

PAYEN, Jean-Charles, «La "mise en roman" du mariage dans la littérature française des XII et XIII ${ }^{\mathrm{e}}$ siècles : de l'évolution idéologique à la typologie des genres », in Willy VAN Hoecke, Andries WelKenhuYsen (dir.), Love and Marriage in the Twelfth Century, Louvain, Leuven University Press, 1981, p. 219-223. 